\title{
RESEARCH ON THE SUITABILITY EVALUATION OF CONSTRUCTION LAND IN SOUTHWEST MOUNTAINOUS AREAS OF CHINA: A CASE STUDY OF BAOXING COUNTY, SICHUAN PROVINCE, CHINA
}

\author{
CAO, M. ${ }^{1,2^{*}}-$ ZHAO, J. ${ }^{1}-$ ZHANG, S. $^{1}$ \\ ${ }^{1}$ School of Tourism management, South China Normal University, Panyu district, No. 378 \\ Waihuan West Road, Guangzhou 510000, Guangdong, P. R. China \\ ${ }^{2}$ Institute of Mountain Hazards and Environment, Chinese Academy of Sciences \& Ministry of \\ Water Conservancy, \#9, Block 4. Renminnan Road, Chengdu 610041 Sichuan, P. R. China \\ *Corresponding author \\ e-mail: caomt@m.scnu.edu.cn; phone:+86-131-2825-1580; fax:+86-20-8521-7757
}

(Received $27^{\text {th }}$ Jun 2018; accepted $6^{\text {th }}$ Sep 2018)

\begin{abstract}
Currently, the threats of mountain disasters are continuously increasing due to the highly vulnerable feedback mechanism of mountain ecosystems, and the construction land use type is most strongly affected by human activities. This study uses multiple index coupling models to evaluate the suitability of construction land. The evaluation uses mountain disaster risk, topographic and geomorphic environments, hydrogeological environments, human activity factors and socio-economic factors as the suitability standards. We use geographic information system (GIS) technology to improve the evaluation model and establish a suitability map of construction land for Baoxing County, Sichuan province, China. This study indicates that the mountain disaster risk is the core factor of the suitability zoning of construction land in Baoxing County, wherein, the development suitability of construction land in the central sectors is relatively high while the mountain disaster risk is relatively high due to the high socioeconomic value of the disaster-bearing areas in the central sectors. The development suitability of construction land near the fracture zones and the natural reserves is relatively low.
\end{abstract}

Keywords: construction land, suitability assessment, mountain disasters, vulnerability, risk assessment

\section{Introduction}

Mountainous areas account for approximately $25 \%$ of the global land area, and the feedback mechanisms in mountain ecosystems are highly vulnerable; therefore, disasters occur frequently (Peng et al., 2016). The characteristics of the limited, easily destroyed and unrestored land resources are obvious, and these characteristics restrict the development, economic value and social benefit of construction land in mountainous areas. At the same time, the international disasters reduction strategy has gradually shifted the "hard" measures of a project to "soft" land planning measures, and land planning limits the development of land in areas where there are disaster potentials (Leroi et al., 2005). All countries and regions throughout the world have combined construction land suitability planning in mountainous areas with research on mountain disasters and have taken the corresponding measures to contribute to the sustainable development of mountainous areas (Hemingway and Gunawan, 2018). For example, the United Nations issued the "Hyogo framework for action 2005-2015: building the resilience of nations and communities to disasters." (ISDR, 2005). Italy has combined hazard risk assessments with land use planning and has applied this theory to actual urban construction. The Advisory Committee, the Planning Association and the United 
States Geological Survey released the "Landslide disasters and Planning: Incorporating Geological disasters Planning into the Planning Process," which notes that land use planning should be focused on reducing the risks of disasters (Lovell, 2010). A series of urban land use plans and natural disaster risk evaluations have become an essential component in the sustainable development of mountainous areas in China. Mountain disaster risk is the most prominent factor in mountain cities and towns, as discussed in., "The National Comprehensive Disaster Prevention and Mitigation Plan (Year 20162020)" and "Outline of National Territorial Planning (Year 2016-2030)," for example (The State Council of China, 2017).

In China, mountainous areas cover 6.66 million $\mathrm{km}^{2}$, accounting for $69.4 \%$ of the territorial areas of China, and the population in mountainous areas is more than $1 / 3$ of the total population (Chen et al., 2010). The mountainous areas are vulnerable to landslides, collapses, mudslides and other mountain disasters, which seriously threaten the safety of lives, property and engineering construction and limit the utilization of land resources and economic development. Therefore, the original resource-rich mountainous areas in China have become the "topographic uplift areas and the economic valley areas" (Cui, 2014).

With the rapid development of urbanization, tremendous changes have taken place in China's mountain towns in terms of construction spatial patterns, population structure and living standards (Liu et al., 2016). Mountain disasters pose a serious threat to people's lives and property (Zhang et al., 2009; Deuskar et al., 2015). Construction land is different from other land types as it is relatively irreversible, and once a piece of land is converted into construction land, it is difficult to restore that land to other land use types. Construction land development that is affected by the mountainous environment and disasters induces and intensifies mountain disasters (Wang, 2012). Additionally, the disaster risk is increasing due to the high economic value of various disaster-bearing areas in the central sections of the mountain towns, which seriously restricts the development suitability of construction land. However, disaster risks are often ignored during construction in mountain towns in China, and scientific evaluations are often not conducted (Jiao et al., 2017). These high-intensity land use development and engineering construction activities may lead to a decline in the environmental carrying capacity and exacerbate the problem of larger population and less land. Many scholars and the Chinese government are aware of the need to correctly understand the correlations among mountainous environment, mountain disasters and construction land development. Moreover, the degree of stress related to mountain disasters needs to be measured, and a suitability evaluation of construction land development needs to be conducted, which would fundamentally guarantee the sustainable utilization of land resources in mountainous areas.

The frameworks of the suitability evaluation for construction land at home and abroad mainly include: 1) Pressure-Status-Response (P-S-R) proposed by Organization for Economic Co-operation and Development (OECD). It mainly illustrates the interrelationship among human activities, social development and ecological environment (Ying et al., 2009; Guo et al., 2003). The advantage of P-S-R framework system is that it can be used for reference to evaluate the suitability of construction land in mountainous areas with fragile natural environment and frequent mountain disasters. However, there is no inevitable logical correlation between the driving force indicator and the state indicator, so it is difficult to quantify the specific indicator, and regional promotion and application are also relatively difficult. 2) Goal-Estimate-Consequence 
(G-E-C) from "The Outline of Land Evaluation" and "The Outline of Sustainable Land Management Evaluation". The goals, types and methods of land use need to be identified first, and on this basis, the judgment results are analyzed (FAO, 1993). The advantage of G-E-C is that the indicators are easily quantified, and the empirical significance is greater. The disadvantage is that the location and social factors of land use are not taken into account, and the economic value and benefit efficiency of land use cannot be fully reflected. As a result, the tracking monitoring and efficiency of economic, environmental and social benefits cannot be comprehensively analyzed and compared, and the optimal layout of land use cannot be determined. 3) NatureEconomy-Society (N-E-S), which is to resolve the land use system to natural, economic and social subsystems under the premise of the comprehensive research on the land use system. This multi-subsystem method can measure the integrity of the system and realize the dimensionality reduction of complex systems (Wang and Bao, 2011). The NE-S framework focuses on the research on other subsystems, rarely discussing the driving mechanism among the ancillary systems. The advantage of this framework is that it can comprehensively and systematically form the unified evaluation of construction land use in the three-dimensional view of nature, economy and society, but there are difficulties in the typicality and regional promotion of some factors in the evaluation system.

Construction land suitability research and evaluation in mountainous areas has mainly focused on the suitability of land for specific uses and the ecological suitability of the land use type. For example, urban construction land has been classified to determine the quality of the land that is suitable for construction at different levels and the areas that are suitable for construction land. The existing soil information system has been utilized to interpret satellite remote sensing images and obtain digital elevation model (DEM) data and map data. An ArcGIS spatial database that includes soil erosion risk data in high-risk areas, land use types, use strength and other land parcel information has been established to combine these layers with the relevant socioeconomic information (Akinci et al., 2013). The superposition slope, flood inundation line, public facilities and other factors have been comprehensively considered to analyze and identify suitable construction land parcels and provide basic data for land use suitability evaluations in mountainous areas (Montanarella and Nègre, 2001; Rusdi et al., 2015).

Statistical and econometric model analysis methods have been used in previous research, and there is an obvious shortage of spatial information processing during simple modeling and quantification. For instance, multifactor comprehensive evaluation models, Markov models, neighborhood algorithms, generalized regression neural network (GRNN) models and fuzzy comprehensive evaluation methods have been used to conduct suitability evaluations of on construction land (Zhou, 2010; Liu et al., 2014; Wei et al., 2014; Qiu et al., 2017).

The advancement of computer-aided superposition mapping methods has resulted in the wide use of technical methods to evaluate construction land suitability in mountainous areas based on ArcGIS. Domestic and foreign researchers have used ArcGIS technology to further the processing of previous econometric models (Nan, 2009; Ambarwulan et al., 2016). Integrated superposition analysis methods, multiindicator decision models, artificial intelligence methods, and mixed data models for vector and raster analysis have been widely used to conduct comprehensive suitability 
judgments for construction land in mountainous areas (Gimblett and Ball, 1994; Malczewski, 2006; Chandio, 2014; Promper et al., 2014).

From the perspective of stress related to mountain disasters, this study combines the unique hazard risks of mountainous areas with the development of construction land suitability based on the actual needs of social and economic development regulations. Baoxing County is a typical mountainous county in Southwest China and is used as an example in this study. After Baoxing County experienced the "5 - 12 Wenchuan Earthquake (Ms 8.0)" in 2008 and the "4 - 20 Lushan Earthquake (Ms 7.0)" in 2013, the number of disaster sites drastically increased, and the hidden dangers of construction land have become more serious (Wu et al., 2016). This study builds multiple coupling models and introduces the risk factors of mountain disasters to evaluates the suitability of construction land in mountain towns. It makes the evaluation results more accurate and reasonable. For the research methods, the weight of other indicators is assessed weight in the suitability evaluation of construction land in mountainous areas in addition to mountain disaster risk factors. The hypermatrix method of the analytic network process (ANP) is adopted so that the correlations among all factors can be fully considered. This study is different from previous research that evaluated the conditions while considering only the relative independence of each factor.

\section{Study area and data sources}

\section{Study area}

Baoxing County $\left(102^{\circ} 28-103^{\circ} 02^{\prime} \mathrm{E}, 30^{\circ} 09^{\prime}-30^{\circ} 56^{\prime} \mathrm{N}\right)$ is located in Sichuan province of China, on the western edge of the Sichuan Basin and north of Ya'an City. Baoxing County borders Wenchuan County and Xiaojin County to the north, Tianquan County to the south, Kangding County to the west and Lushan County in the east. The transportation is mainly based on highways, and provincial highway No. 210 runs throughout the territory. The county is $61 \mathrm{~km}$ wide from east to west and $81 \mathrm{~km}$ long from south to north, and the jurisdiction area is approximately $3114 \mathrm{~km}^{2}$ (Fig. 1).

\section{Data sources}

Statistics used in this study is originated from field investigations of Land use of Baoxing county, Sichuan province China in 2016-2017 of institute of Mountain Hazards and Environment, Chinese Academy of Sciences \& Ministry of Water Conservancy. The main types of mountain disasters in the county are collapses, landslides and mudslides. At present, there are a total of 337 disaster sites, including 153 landslides, 144 collapses and 40 mudslides. The density of dangerous areas is $8.49 \mathrm{~m}^{2} / \mathrm{km}^{2}$, and the hazard volume density is $105.4110^{4} \mathrm{~m}^{3} / \mathrm{km}^{2}$. The threatened population is 15,750 , accounting for $26.71 \%$ of the total population in the county. The total area of construction land in the county is $2,456.67 \mathrm{hm}^{2}$. The urban and rural land for industry and mining, land for highways and water and land for water conservation facilities (including reservoir water and hydraulic construction land) constitute areas of $1714.66 \mathrm{hm}^{2}, 219.88 \mathrm{hm}^{2}$ and $522.12 \mathrm{hm}^{2}$, respectively, accounting for $69.80 \%, 8.95 \%$ and $21.25 \%$ of the total construction land area in the county, respectively.

The latest DEM (1:50000 data), administrative division maps, present land use map, river system map, fracture structure map, traffic roadmaps, and population and related socio-economic data were obtained in accordance with the mountain disasters tracking 
survey and construction land development in Baoxing County from research groups between 2014 and 2016. The data originate from the Statistical Bureau, Meteorological Bureau, Land Bureau, archives, geological environment monitoring stations and other relevant government departments of Baoxing County.
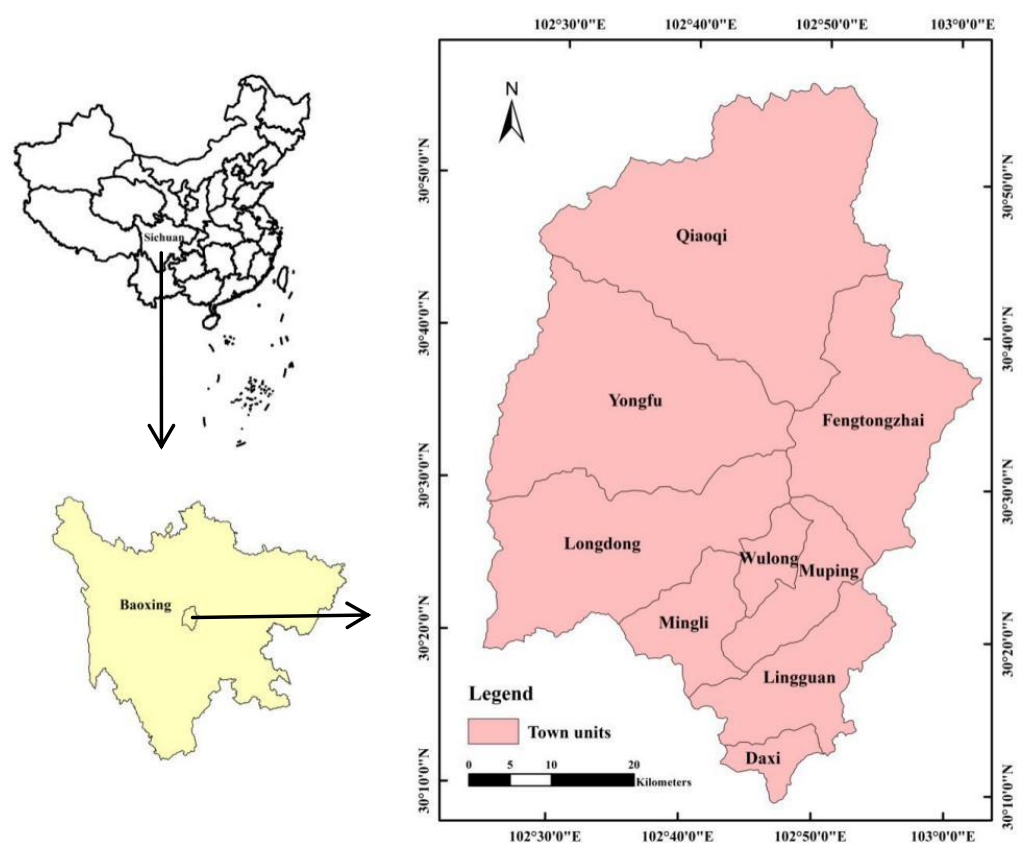

Figure 1. Title of the given figure, graph or image included in the document

To facilitate the matching of the vector and raster data, this study first utilized ArcGIS to process the evaluation units of the study area into a square $25 \mathrm{~m} \times 25 \mathrm{~m}$ grid. Administrative units were then utilized to perform the regional calculations and evaluate the results of the previous grid unit and obtain the data for each grid unit in each administrative unit. The grid format is convenient for the subsequent comprehensive comparison and analysis. The grid unit is more precise than the land use patches, land types and soil units that have been used previously. Moreover, the land use evaluation attributes are more homogeneous in a grid unit, which improves the accuracy of the evaluation results. The grid unit format is consistent with that of ArcGIS raster data, and the use of computer processing is relatively simple. Additionally, the research results are conducive to the ultimate implementation by the relevant departments of the Chinese government.

\section{Model methods}

\section{Mountain disaster risk evaluation models}

The analysis of mountain disasters risks, the degree of mountain disasters influence and the degree of vulnerability of hazard-bearing areas are comprehensively studied based on the analysis of mountain disaster risks. To balance the process of the differences in the influencing degree, this study mainly determined the models for hazard risk evaluations in the study area according to the hazard degree and the degree of mountain disaster vulnerability. 
The degree of mountain disasters is closely related to the density of disasters in an environment, and the relative surface structure and tectonic environment indicators were selected. The number, area and volume of 337 disaster sites in Baoxing County were used to determine the contribution rate of each indicator to the development of mountain disasters (Change, 2007). The weight of each indicator and the mutual weight between various indicators were obtained to establish the formula for the degree of mountain disasters, which can be presented as follows (Eq. l):

$$
H_{j}=w_{i} w_{i j} X_{i}
$$

where $H_{j}$ refers to the degree of mountain disasters; $w_{i}$ indicates the self-weight; $w_{i j}$ indicates the mutual weight; and $X_{i}$ denotes the independent variable of the indicator.

The degree of mountain disaster vulnerability is correlated with the possibility for hazard damage and the difficulty level of repairing the damage to the hazard-bearing areas in the county (UNDP, 2004; ADRC,2005; Cardona, 2005; Smith, 2013). The relevant indicators are selected according to the actual situation, and the indicator weight can be represented as a multiplicative summation of the individual and mutual weight of each indicator and the indicator weight value to establish the formula for the degree of mountain disaster vulnerability, which can be determined using Equation 2:

$$
V_{S}=\sum_{t=1}^{n} W_{z} W_{h} y
$$

where $V_{S}$ represents the degree of mountain disasters vulnerability; $W_{z}$ indicates the individual weight; $W_{h}$ means the mutual weight; and y refers to the independent variable of the indicator.

Based on Equations 1 and 2, the formula for the comprehensive degree of mountain disaster risk $\left(R_{I}\right)$ is obtained as follows $(E q .3)$ :

$$
R_{I}=H_{j} \cdot V_{S}=w_{i} w_{i j} X_{i} \cdot \sum_{t=1}^{n} W_{z} W_{h} y
$$

\section{Models to evaluate the suitability of construction land development under the stress of mountain disasters}

The present land use patterns and the layout of construction land in the study area were taken into account, and the prohibited development areas (areas with slopes greater than $25^{\circ}$, areas within $100 \mathrm{~m}$ of fracture zones and core-protected areas) were excluded. The important factors that affect the suitability of construction land in mountainous areas were analyzed, and an evaluation indicator system was established. The weights of the ANP evaluation indicators were obtained by using Super Decisions software, and the comprehensive scores of various indicators were calculated on the grid unit. The ANP uses the hypermatrix method to quantify the degree of influence between indicators and can more objectively and effectively express the complex practical problems than the analytic hierarchy process (AHP). Many decision-making problems cannot be simply expressed as hierarchical structures, and the various levels of elements are interactional and interdependent. The formula to model the suitability of construction land development can be expressed as follows (Eq. 4): 


$$
L_{s}=\sum_{i=1}^{\mathrm{n}} Z_{j, i}(f, w)
$$

where, $L_{S}$ indicates the total score; $j$ refers to the $j^{\text {th }}$ evaluation unit; $i$ denotes the $i^{\text {th }}$ indicator; $\mathrm{n}$ represents the number of indicators; $f$ means the score of the indicator; and w stands for the weight of the indicator. When the calculated value of $L_{S}$ is high, it indicates that the level of the suitability of construction land will be higher.

Based on Equations 3 and 4, the calculation formula for the suitability of construction land under the stress of mountain disasters is determined as follows (Eq. 5):

$$
O_{H}=K_{i} \cdot R_{I} \cdot L_{s}
$$

where, $O_{H}$ refers to the suitability of construction land under the disaster stress; $R_{I}$ denotes the comprehensive risk degree of mountain disasters; $L_{S}$ indicates the suitability of construction land under the non-disaster stress; and $K_{i}$ means the coefficient of variation, with a value range of $0 \sim 1$. The value of $K_{i}$, the coefficient of variation, is mainly based on the different types of the present situation of construction land in the study area.

\section{Analysis of mountain disaster risk and design of evaluation indicators}

\section{Analysis of hazard classification of mountain disasters}

The degree of mountain disasters is closely related to various factors of the hazardprone environment, including surface structure and hydrological structure conditions. Based on the evaluation methods and factor selection used in previous studies, this study focuses on selecting indicators that play a leading role in the degree of mountain disasters in Baoxing County and are convenient for the collection of spatial data. The surface structure factors can be extracted directly from the digital elevation data of the 1:50000 DEM for Baoxing County using ArcGIS software. These factors include the relative height difference, slope, slope aspect and slope shape. The influence on the development of mountain disasters becomes more significant as the relative height increases. It is easier for disaster sites to develop as the steepness of the slope increases. The slope aspect has a remarkable influence on mountain disasters. The south slope typically has the highest solar radiation, and the north slope has the lowest. The light, temperature, precipitation, wind speed and soil vegetation all differ between the windward and leeward slopes. A concave slope is a mature stage that is more stable and has fewer developed disaster sites. A convex slope is in a period of intense evolution, and there are more developed disaster sites. The number of disaster sites on a straight slope is between that of a convex slope and a concave slope. The tectonic environmental factors are extracted using the Proximity Analysis tools in ArcGIS. The distance from rivers and the distance from fracture zones are determined using a buffer analysis. Rivers have a significant influence on the formation and development of disaster sites, and the instability of the geological conditions and the susceptibility of the area is to developing disaster sites increase for areas closer to a fracture zone.

The spatial analyst function in ArcGIS was used to import the classification layers of various indicators, and the Raster calculator was adopted to superimpose the hazard 


$$
-6574-
$$

degree indicators to obtain the value of the comprehensive mountain disaster risk for each evaluation unit according to the previously described formula. The continuous hazard degree partition was divided into equal intervals and reclassified. Identical cells were merged, and the degree partition of mountain disasters was conducted. A higher degree of mountain disasters is associated with the higher contribution of each indicator to the occurrence of mountain disasters.

As seen from Table 1 and Figure 2, the area of the region in Baoxing County with the lowest degree of mountain disasters (the low-hazard region) is $55,000 \mathrm{~km}^{2}$, accounting for $17.65 \%$ of the total county area.

Table 1. The distribution of mountainous disasters hazard classification

\begin{tabular}{c|c|c|c|c|c}
\hline \multirow{2}{*}{ Type/level } & \multicolumn{2}{|c|}{ Area } & \multicolumn{3}{c}{ Disaster spots } \\
\cline { 2 - 6 } & Number/hm & Percentage/\% & Number & Percentage/\% & Density/hm $\mathbf{h}^{\mathbf{2}}$ \\
\hline Low-hazard region & 55,000 & 17.65 & 55 & 16.32 & 0.10 \\
Medium-hazard region & 155,400 & 49.87 & 193 & 57.27 & 0.12 \\
High-hazard region & 101,189 & 32.48 & 89 & 26.41 & 0.09 \\
\hline
\end{tabular}

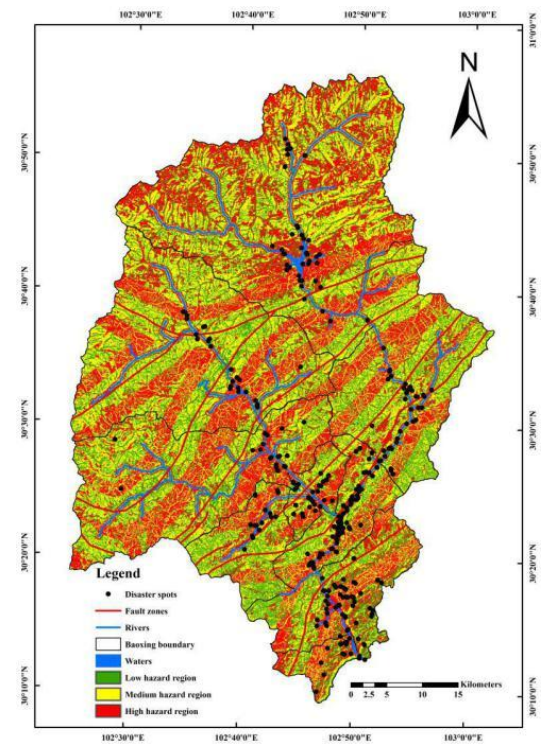

Figure 2. The distribution map of mountain disasters hazard in Baoxing

Within this region, 55 disaster sites, which account for $16.32 \%$ of the total disaster sites, are distributed in Fengtongzhai Township and Mingli Township, and the density is $0.10 / \mathrm{hm}^{2}$. The area of the region with a medium degree of mountain disasters (the medium-hazard region) is $155,400 \mathrm{~km}^{2}$, accounting for $49.87 \%$ of the total county area. Within this region, 193 disaster sites that account for $57.27 \%$ of the total number of disaster sites, are located in Muping Town, Lingguan Town, Longdong Town and Yongfu Township, and the density is $0.12 / \mathrm{hm}^{2}$. The area of the region with a high degree of mountain disasters (the high-hazard region) is $101,189 \mathrm{~km}^{2}$, accounting for $32.48 \%$ of the total county area. Within this region, 89 disaster sites that account for $26.41 \%$ of the total number of disaster sites are distributed along rivers and near fracture 
zones in Qiaoqi Tibetan Township, Wulong Township and Daxi Township, with the density of $0.09 / \mathrm{hm}^{2}$.

\section{Analysis of mountainous disasters vulnerability classification}

The degree of mountain disaster vulnerability is affected by socio-economic conditions and the conditions of hazard-affected areas. The socio-economic conditions include the spatial distribution of the population, land resources, water resources, transport facilities, large enterprises and other factors. The conditions of hazard-affected areas contain the type, quantity, and value of hazard-affected areas. In socioeconomically developed regions, there is a dense population, intensive urbanization, highly concentrated industrial activities, numerous dense hazard-affected areas with high economic value, and the probability of damage from a wide range of mountain disasters is great, leading to the corresponding increase in casualties and economic losses. In view of this, this study selects six indicators for analysis, namely, population density, gross domestic product (GDP) density, fixed asset density, threatened property density, road density and land resource abundance for analysis.

The spatial analyst function in ArcGIS was used to import the classification layers of various indicators. According to the above formula, the Raster calculator was adopted to superimpose the vulnerability indicators to obtain the degree of hazard vulnerability value for each evaluation unit. The raster was reclassified. Identical cells were merged, and the vulnerability degree partition of mountain disasters was conducted. A higher vulnerability degree value indicates a higher degree of mountain disasters vulnerability. The study area is divided into three regions according to the degree of vulnerability, namely, the high-vulnerability region, the medium-vulnerability region, and the lowvulnerability region.

As seen from Table 2 and Figure 3, the degree of vulnerability is higher where the density of disaster sites is greater. In Baoxing County, the area of the low-vulnerability region accounts for $83.22 \%$ of the total county area.

Table 2. The distribution of mountain disasters vulnerability region degree level disaster spots

\begin{tabular}{c|c|c|c|c|c}
\hline \multirow{2}{*}{$\begin{array}{c}\text { Type/vulnerability degree } \\
\text { level }\end{array}$} & \multicolumn{2}{|c|}{ Area } & \multicolumn{3}{c}{ Disaster spots } \\
\cline { 2 - 6 } & Number/hm & Percentage/\% & Number & Percentage /\% & Density/hm \\
\hline Low-vulnerability region & 259289 & 83.22 & 141 & 41.84 & 0.05 \\
Medium-vulnerability region & 40000 & 12.84 & 149 & 44.21 & 0.37 \\
High-vulnerability region & 12300 & 3.95 & 47 & 13.95 & 0.38 \\
\hline
\end{tabular}

Within this region, 141 disaster sites account for $41.84 \%$ of the total disaster sites in the county, and these sites are mainly distributed in Qiaoqi Tibetan Township, Yongfu Township, Fengtongzhai Township and Mingli Township, with the density of $0.05 / \mathrm{hm}^{2}$. The area of the medium-vulnerability region accounts for $12.84 \%$ of the total county area. Within this region, 149 disaster sites, $44.21 \%$ of the total disaster sites in the county, are located in Muping Town and Lingguan Town, and the density is $0.37 / \mathrm{hm}^{2}$. The area of the high-vulnerability region accounts for $3.95 \%$ of the total county area. Within this region, 47 disaster sites, accounting for $13.95 \%$ of the total in the county, are in Wulong Township and Daxi Township, and the density is $0.38 / \mathrm{hm}^{2}$. 


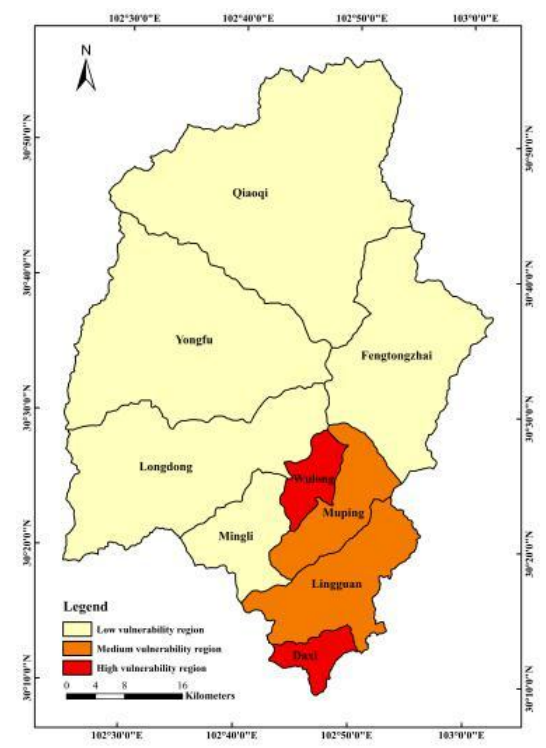

Figure 3. The distribution map of mountain disasters in Baoxing

\section{Interpretation of the comprehensive risk degree partition of mountain disasters}

Based on the above mentioned results of the hazard degree and partitions of hazard vulnerability degree, the value of the comprehensive degree of mountain disasters risk of each evaluation unit is calculated in accordance with the formula. ArcGIS is used to reclassify the raster. Identical cells are merged, and the comprehensive degree partition of mountain disasters risks is obtained.

As shown in Table 3 and Figure 4, the low-risk region in Baoxing County is located in Fengtongzhai Township and Mingli Township, covering an area of 55,000 $\mathrm{hm}^{2}$, which accounts for $17.65 \%$ of the total county area. The medium-risk region is distributed in Yongfu Township and Longdong Town, covering an area of 115,400 $\mathrm{hm}^{2}$, which accounts for $37.04 \%$ of the total county area. The high-risk region is located in Qiaoqi Tibetan Township, Wulong Township, Muping Town, Lingguan Town and Daxi Township and is mainly on the periphery of the buffered areas of rivers and fracture zones. The high-risk region covers an area of $141,189 \mathrm{hm}^{2}$, accounting for $45.31 \%$ of the total county area. In general, there are more disaster sites in the areas near fracture zones and rivers, but there are fewer hazard-affected areas in these regions. However, in the peripheral regions, there are more hazard-affected areas and the economic value is higher. Therefore, the potential losses are greater, and the risks are higher in the peripheral regions.

Table 3. Mountain disasters comprehensive risk degree partition results

\begin{tabular}{c|c|c|c|c|c}
\hline \multirow{2}{*}{$\begin{array}{c}\text { Type/risk degree } \\
\text { level }\end{array}$} & \multicolumn{2}{|c|}{ Area } & \multicolumn{3}{c}{ disaster spots } \\
\cline { 2 - 6 } & Number/hm & Percentage /\% & Number & Percentage /\% & Density/hm $\mathbf{~}^{\mathbf{2}}$ \\
\hline Low-risk region & 55000 & 17.65 & 55 & 16.32 & 0.10 \\
Medium-risk region & 115400 & 37.04 & 44 & 13.06 & 0.04 \\
High-risk region & 141189 & 45.31 & 238 & 70.62 & 0.17 \\
\hline
\end{tabular}




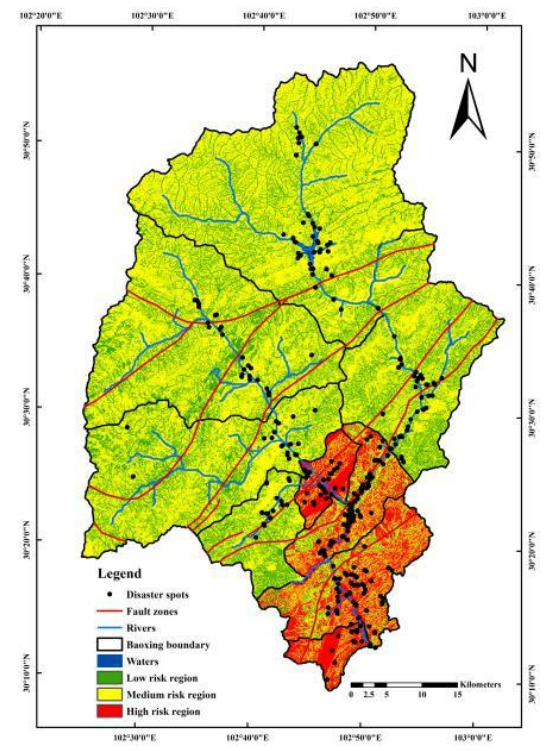

Figure 4. The distribution map of mountain disasters risk in Baoxing

\section{Design of evaluation indicators for construction land development suitability}

The surface structure factors

Baoxing County is a typical mountainous county, and the layout of its construction land, which is mainly segmented by mountains, rivers and gullies, is scattered. This layout is not conducive to construction land sustainability or infrastructure construction. Areas with slopes greater than $25^{\circ}$ are directly classified as prohibited construction areas by the relevant land regulations in China, So the score is 0. Altitude, slope aspect and relief amplitude also play key roles in the stability and safety of buildings, the difficulty of construction and the costs of construction, and these factors directly restrict the layout of land use, the choices of roads and the spatial distribution patterns of buildings.

As can be seen from Table 4, we classify and assign values based on the proportion of the number of disaster sites in the developing mountains. The slope is within the $0-5^{\circ}$ range, and the proportion of developed mountain disaster points accounts for $3.56 \%$ of the total, and within the $5-8^{\circ}$ range, $5.90 \%, 8-15^{\circ}, 7.67 \% ; 15-25^{\circ}, 25.82 \%$, greater than $25^{\circ}, 56.97 \%$, it can be seen that the smaller the slope, the less likely the development disaster point, so the higher the score, the higher the suitability of the construction land. Less than $800 \mathrm{~m}$ above altitude, the proportion of mountain disaster sites is $14.24 \%$, $800-1200 \mathrm{~m}, 15.13 \%, 1200-1600 \mathrm{~m}, 19.58 \%, 800-1600 \mathrm{~m}, 16.32 \%$, greater than $2000 \mathrm{~m}, 34.72 \%$. The higher the altitude, the greater the probability of developing disaster points, the lower the score, and the lower the suitability of the construction land. Similarly, the greater the topography fluctuation, the greater the relative height difference, the less suitable for construction. From the slope aspect of view, the proportion of mountain disaster sites developed on the southern slope is 5.93\%. The Northern slope is $9.50 \%$, the Northwest slope is $10.09 \%$, the Eastern slope is $10.68 \%$, the Southwest slope is $13.06 \%$, the Northwest slope is $13.06 \%$, the southeast slope is $18.69 \%$, the Western slope is $18.99 \%$. The more disaster points developed up each slope, the lower the score, the less suitable it is to build. 
Table 4. The surface structure factors' class interval, assign and layer

\begin{tabular}{|c|c|c|c|}
\hline Indicators name & Class interval & Score & Layer \\
\hline \multirow{5}{*}{$\begin{array}{l}\text { Slope } \\
\left({ }^{\circ}\right)\end{array}$} & $<5$ & 5 & \\
\hline & $5-8$ & 4 & \\
\hline & $8-15$ & 3 & \\
\hline & $15-25$ & 2 & \\
\hline & $>25$ & 0 & \\
\hline \multirow{5}{*}{$\begin{array}{l}\text { Altitude } \\
\text { (m) }\end{array}$} & $<800$ & 5 & \\
\hline & $800-1200$ & 4 & \\
\hline & $1200-1600$ & 3 & \\
\hline & $1600-2000$ & 2 & \\
\hline & $>2000$ & 1 & \\
\hline \multirow{5}{*}{$\begin{array}{l}\text { Relief amplitude } \\
\text { (m) }\end{array}$} & $<100$ & 5 & \\
\hline & $100-200$ & 4 & \\
\hline & $200-300$ & 3 & \\
\hline & $300-400$ & 2 & \\
\hline & $>400$ & 1 & \\
\hline \multirow{4}{*}{ Slope aspect } & Southern slope/Northern slope & 5 & \\
\hline & Northwest slope/Eastern slope & 4 & \\
\hline & Southwest slope/Northwest slope & 3 & \\
\hline & Southeast slope/Western slope & 2 & \\
\hline
\end{tabular}

\section{Hydrogeological factors}

Due to the constant movements of geological structures in mountainous areas and the long-term effects of river water erosion, the complex hydrogeological environment greatly hinders the development of construction land. The drainage conditions have an important influence on the development of construction land and the construction of a project, and good drainage conditions can reduce construction costs. The cumulative amount of running water was used to measure the displacement of land in the study area, and the drainage conditions were considered to be worse if the cumulative amount of running water was large.

As shown in Table 5, the rock formations in mountainous areas are complex, and generally speaking, areas that are farther away from fault zones are more suitable for 
construction due to the higher stability and safety. In terms of the number of disaster sites, the proportion of mountain disaster sites is $33.23 \%$ within $500 \mathrm{~m}$ of the fault zone. The $500-1000 \mathrm{~m}$ range is $24.63 \%, 1000-2000 \mathrm{~m}$ is $13.35 \%, 2000-4000 \mathrm{~m}$ is $17.51 \%$, greater than $4000 \mathrm{~m}$ is $11.28 \%$. It can be seen that the farther the distance from the fault zone, the higher the construction score, the more suitable construction.

Table 5. Hydrogeological factors' class interval, assign and layer

\begin{tabular}{|c|c|c|c|c|}
\hline Indicators name & Unit & Class interval & Score & Layer \\
\hline \multirow{5}{*}{ Drainage condition } & \multirow{5}{*}{$\left(\mathrm{m}^{3}\right)$} & $>25$ & 5 & \\
\hline & & $15-25$ & 4 & \\
\hline & & $8-15$ & 3 & \\
\hline & & $5-8$ & 2 & \\
\hline & & $<5$ & 1 & \\
\hline \multirow{5}{*}{$\begin{array}{c}\text { Distance from the fault } \\
\text { zones }\end{array}$} & \multirow{5}{*}{$(\mathrm{m})$} & $>4000$ & 5 & \\
\hline & & $2000-4000$ & 4 & \\
\hline & & $1000-2000$ & 3 & \\
\hline & & $500-1000$ & 2 & \\
\hline & & $100-500$ & 1 & \\
\hline \multirow{5}{*}{ Distance from the rivers } & \multirow{5}{*}{$(\mathrm{m})$} & $<500$ & 5 & \\
\hline & & $500-1000$ & 4 & \\
\hline & & $1000-1500$ & 3 & \\
\hline & & $1500-2000$ & 2 & \\
\hline & & $>2000$ & 1 & \\
\hline \multirow{5}{*}{$\begin{array}{l}\text { Distance from the water area } \\
\text { (lakes, reservoirs, etc.) }\end{array}$} & \multirow{5}{*}{$(\mathrm{m})$} & $>3000$ & 5 & \\
\hline & & $2000-3000$ & 4 & \\
\hline & & $1500-2000$ & 3 & \\
\hline & & $1000-1500$ & 2 & \\
\hline & & $<1000$ & 1 & \\
\hline
\end{tabular}

The fluvial action of rivers has a significant effect on the formation of landform types, and the distance from rivers is directly related to the guarantee for water supply in urban construction. The water supply conditions for construction land near rivers are better, which increases the suitability. In addition, the distance from water (lakes, reservoirs, etc.) can reflect the degree of water pollution, especially the pollution from 
domestic waste and industrial wastewater. Among them, the water conditions within $500 \mathrm{~m}$ are the best, so the score is 5 . According to field survey studies, for each additional $500 \mathrm{~m}$, the water level is reduced by one level, and when the water conditions after the distance is greater than 2,000 $\mathrm{m}$ do not have a significant impact, so, We divide each classification according to such a rule.

The water area in this study refer to the planar distributed areas except for rivers, lakes and reservoirs. Residential areas, factories and other related public production and living facilities should be located far away from the safe distance range of waters to reduce the influence of water pollution sources. The ecology of the water area is fragile, and the closer it is to the water area, the less suitable it is for construction. Therefore, we follow the distance from far to near, and the score is from high to low.

\section{Human activity factors}

Human activities have a remarkable impact on the development of construction land in mountainous areas (Bucała, 2014; Chen et al., 2016). In this study, the current land use conditions were selected as an indicator, which can reflect the land use types. As shown in Table 6, industrial and mining lands and Waterworks construction land have large number of construction projects, so the suitability for construction land is higher, that is why we scored highest in our classification. The suitability of dry land and other land is lower than the land mentioned above, but it is higher than forest land, grassland, etc., so the score is second. Moreover, forest land and grassland are highly vulnerable ecologically, and the development and construction costs are high there, so the suitability is lower. Paddy fields and water area (lakes, reservoirs, etc.) can hardly be used for construction. The distance from the built-up areas is also selected as an indicator. Here, built-up areas refer to the tracts where construction has been completed throughout the county, and these areas are the economic growth point, with strong agglomeration and radiation effects. In general, areas closer to built-up areas are more suitable for construction land development due to lower construction costs. The distance from the roads is selected as another indicator that can reflect the accessibility of the regional roads, and the conditions of these roads affect the cost of construction and the development of urban construction land. The suitability of construction land will be higher when the distances between roads are shorter. Finally, the core areas and the periphery of protected areas were selected as indicators. Protected areas have high ecological sensitivity and are banned as construction areas, whereas the areas outside the core-protected areas are more suitable for construction.

Table 6. Human activities factors and indicators' class interval, assign and layer

\begin{tabular}{c|c|c|}
\hline Indicators name & Class & Score \\
\hline \multirow{4}{*}{$\begin{array}{c}\text { The present situation } \\
\text { of land use }\end{array}$} & $\begin{array}{c}\text { Industrial and mining land in city, } \\
\text { waterworks construction land }\end{array}$ & 5 \\
\cline { 2 - 3 } & Dry land, other land & 4 \\
\cline { 2 - 3 } & Forest land & 3 \\
\cline { 2 - 3 } & Paddy fields, water area (lakes, reservoirs, \\
etc.) & 1 & Garden land, grassland \\
\hline
\end{tabular}




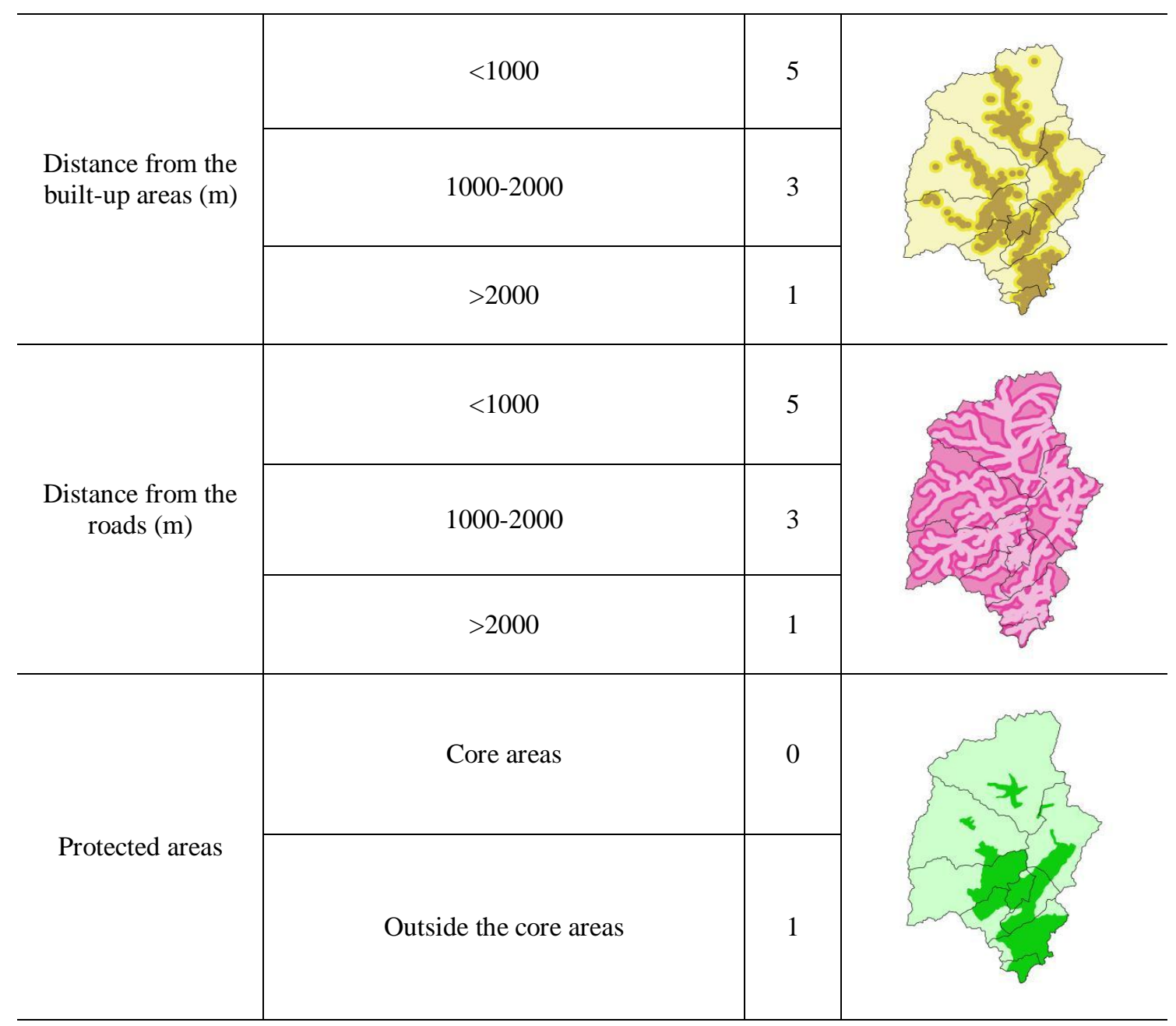

\section{Analysis of the assessment of construction land evaluation results}

\section{Analysis of evaluation indicator weight}

An evaluation indicator system was established using ANP, and the weight of each indicator was calculated using Super Decisions software based on the evaluation indicator selection described above (Table 7).

Table 7. Evaluation indicator weight for construction land development suitability

\begin{tabular}{c|c|c|c}
\hline Evaluation indicator & Weight & Evaluation indicator & Weight \\
\hline Slope & 0.1547 & Distance from the rivers & 0.0881 \\
Altitude & 0.1404 & Distance from the waters (reservoirs) & 0.0610 \\
Relief amplitude & 0.0468 & The present situation of land use & 0.2074 \\
Slope aspect & 0.0213 & Distance from the built-up areas & 0.0397 \\
Drainage condition & 0.0662 & Distance from the roads & 0.1110 \\
Distance from the fracture zones & 0.0475 & Protected areas & 0.0159 \\
\hline
\end{tabular}

The Raster calculator function from the spatial analyst tools for ArcGIS10.1 software was used to calculate various evaluation indicators according to the formula, and obtain 
the suitability partition of construction land development in Baoxing County. The construction land suitability level was divided into four categories based on natural breaks classification, and then the regional mean value was used to calculate the spatial distribution of construction land suitability in various townships and towns of the county.

\section{Analysis of evaluation construction land suitability level results}

Based on the above results of the mountain disaster risk partitioning and the evaluation indicator weight for construction land development suitability, the coupling model formula was used with the Raster calculator function from the in spatial analyst tools for in ArcGIS. To visually show the analysis results, the spatial analyst reclassification was used to classify the suitability levels into 4 categories according to natural breaks classification. We then determined the construction land suitability levels under the stress of mountain disasters (Table 8).

Table 8. Construction land suitability level results under the stress of mountain disasters

\begin{tabular}{c|c|c|c}
\hline Suitability degree level & Number of grid cells & Area $\left.\mathbf{( h m}^{\mathbf{2}}\right)$ & Percentage (\%) \\
\hline High-suitability region & 451 & 28.318 & 0.009 \\
Medium-suitability region & 6516 & 409.136 & 0.131 \\
Low-suitability region & 52028 & 3266.806 & 1.048 \\
Unsuitability region & 4903453 & 307884.741 & 98.811 \\
\hline
\end{tabular}

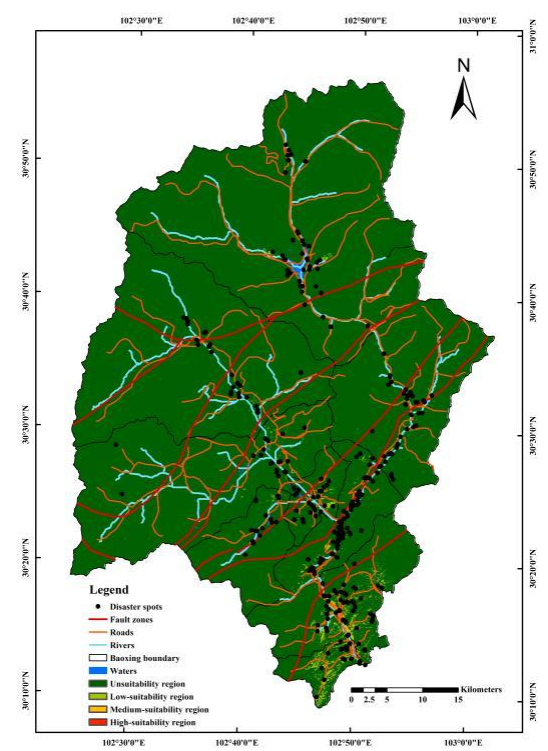

Figure 5. Construction land suitability degree level in Baoxing

As shown in Table 6 and Figure 5, the high-suitability region is the smallest area of the four land types and covers an area of $28.318 \mathrm{hm}^{2}$, which accounts for $0.009 \%$ of the total county area. The high-suitability region is mainly located southwest of Baoxing County, mostly in Wulong Township, Muping Town, Lingguan Town and Daxi Township. The highway mileage in this region is $286.7 \mathrm{~km}$, and the traffic conditions 
and the hazard emergency rescue and response conditions are good. For example, in this region, there are 7 hospitals and health centers, 107 practicing (assistant) physicians and 197 medical beds, which account for $58.33 \%, 75.89 \%$ and $79.76 \%$ of the county's total for each of these services, respectively. Most areas of the regions are built-up areas with good infrastructure. There are 16 villages with broadband networks, 26 villages with cable TV, 27 villages with tap water and 20 villages with centralized waste disposal, accounting for $72.73 \%, 50.00 \%, 49.09 \%$ and $52.63 \%$ of the county's total for each of these services, respectively. In addition, the region has high economic value for construction land, and high suitability for construction land development. Nevertheless, these conditions are also associated with higher economic density, land value and construction costs. Moreover, if a disaster occurs, there will be substantial losses will be caused, and the hazard risks will be high.

The medium-suitability region covers an area of $409.136 \mathrm{hm}^{2}$, which accounts for $0.131 \%$ of the total county area, and the region is located mainly on the periphery of the high-suitability land. Most parts of this region are cultivated land and rural residential areas, with better land drainage conditions, longer highways, better traffic accessibility conditions, higher population densities and higher per capita GDP. In general, compared with the high-suitability region, the conditions of this region are worse, and it is closer to built-up areas.

The low-suitability region covers an area of $3266.806 \mathrm{hm}^{2}$, which accounts for $1.048 \%$ of the total county area. Generally, the conditions here are worse than those of the medium-suitability region. Specifically, its hazard rescue and response capabilities are weaker, and there are only 3 hospitals, 11 practicing (assistant) physicians and 25 medical beds, which account for $25.00 \%, 7.80 \%$ and $10.12 \%$ of the county's total for each of these services, respectively.

Located on the periphery of the low-suitability land, the region that is unsuitable for construction land development covers an area of $307884.741 \mathrm{hm}^{2}$, which accounts for $98.811 \%$ of the total county area. It covers the largest area in the county, mainly because the Fengtongzhai Nature Reserve, a giant panda protection base is sited there. In addition, the region has a better natural ecological environment, higher vegetation coverage and is far away from the town center, suggesting that there is less interference by human production and living activities. Moreover, this region is regarded as a nature conservation area and development is prohibited there.

\section{Conclusions and discussion}

\section{Conclusions}

Based on the results indicate that the disaster spots have a significant impact on the suitability of construction land and are directly related to the future development and construction of land resources. At the same time, the built-up areas are smaller than those in the suitable land in Baoxing County, meaning potential for future construction land development in the county. With the continuous improvement of technology, the construction of hazard prevention and mitigation project and the further reduction of hazard stress degrees, more land will likely be available for construction. We also find that the mountain disaster risk is the core factor for the suitability evaluation of the urban construction land in mountainous areas. And the central areas of the mountain towns are the high-risk and high-suitability areas for the development of construction land. 


\section{Discussion}

In view of the above evaluation results, this study proposes construction land development paths in Baoxing County, which mainly include the following aspects:

There is a need to establish a planning system that combines construction land with mountain disasters, and the planning and design must comply with the relevant laws and regulations to ensure the standardized development of construction land. All projects under construction in the county must strictly conduct an mountain disasters risk evaluation, especially during the planning and site selection for town relocation and major projects.

Hazard monitoring and construction should be carried out simultaneously in the high-risk high-suitability construction regions. In the county, the high-suitability construction region is also the high-risk region. There are good regional land use conditions, complete public infrastructure, high value-added land use benefits, good traffic accessibility and high vulnerability and high risks of mountain disasters. It is necessary to conduct real-time monitoring and provide early warning for schools, hospitals, industrial and mining enterprises, scenic spots, special land and other hazardbearing bodies with weak hazard resistance abilities in the region. Moreover, targeted measures must be taken, especially for industrial and mining land, which has a serious hidden danger of mountain disasters and poses a threat to the safety of residents during production, life and travel. It is necessary to combine the regional industrial bases, consider the land function orientation and develop corresponding supporting facilities, so as to improve value and transfer the benefits of construction land assets and achieve better development of the high-risk high-suitability region.

Construction land in rural residential areas should be integrated into the mediumsuitability construction region. In this region, new rural construction will be achieved mainly by integrating construction land in rural residential areas. It is necessary to dismantle and merge villages, renovate hollow villages and construct center villages according to local conditions and improve the utilization efficiency of rural homesteads. There is a small amount of urban industrial and mining land in this region, so it is necessary to rely on the county to integrate regional space, promote the division of labor and cooperation between the villages and towns and realize the complementary advantages. In this way, the comprehensive carrying capacity of the county can be improved to fully enhance the overall land use efficiency.

The low-suitability construction region is mainly remote and poverty-stricken areas, which are dominated by agricultural land and bare land. It has a large proportion of idle land, and low per capita net income of farmers. Most of its population belongs to the left-behind elderly, left-behind children and the disabled, and these result in the high vulnerability of this region. Therefore, there is a need to ease the burden on farmers, reduce the prices of agricultural chemical fertilizers and other production materials, develop and utilize the idle land resources and implement precise poverty alleviation measures. Sustainable land use can also be promoted by arranging the idle land and changing the land use patterns. For instance, idle old factories can be converted into a breeding base for farmers, and old rural homesteads can be changed into new housing land.

A protected land network system should be constructed in the unsuitable construction area. The core area of the protected land in this region is habitat for the giant panda. The construction of the protected land network has restricted the sustainable livelihoods of the surrounding farmers to a certain extent. Due to their sole reliance on the fiscal 
transfer payments and ecological compensation from the government, the transformation of the livelihoods of farmers will be faced with challenges.

As a result, when the Chinese government establishes and manages a protected land network, the connection between resource management and the needs of community residents should be considered, and corresponding supportive strategies should be implemented. For instance, the characteristic industry of Baoxing County and a labor export strategy, as well as an ecotourism strategy, can bring a more diversified selection of livelihood strategies for local farmers.

Acknowledgements. We thank all funding support from the science and technology program in Guangdong province of China (Grant No.: 2017A020220009), the 61st batch of Chinese postdoctoral program (Grant No.: 2017M612683), the south China normal university youth teacher scientific research cultivating fund program (Grant No.: 2016JK102). Our Special thanks to Prof. Shaoquan Liu and A/Prof. Li Peng for their help.

\section{REFERENCES}

[1] Akinci, H., Ozalp, A. Y., Turgut, B. (2013): Agricultural land use suitability analysis using GIS and AHP technique. - Computers and electronics in agriculture 97: 71-82.

[2] Ambarwulan, W., Santoso, P. B., Sabiham, S., Hikmat, M. (2016): Remote sensing and land suitability analysis to establish local specific inputs for paddy fields in Subang, West Java. - Procedia Environmental Sciences 33: 94-107.

[3] Bucała, A. (2014): The impact of human activities on land use and land cover changes and environmental processes in the Gorce Mountains (Western Polish Carpathians) in the past 50 years. - Journal of Environmental Management 138: 4-14.

[4] Cardona, O. D. (2005): Indicators of Hazard Risk and Risk Management: Program for Latin America and the Caribbean: Summary Report. - Inter-American Development Bank, Washington, DC.

[5] Center, A. D. R. (2005): Total Hazard Risk Management: Good Practices. - Handbook for the UN World Conference on hazard Reduction, Kobe.

[6] Chandio, I. A., Matori, A. N., Yusof, K., Talpur, M. H., Aminu, M. (2014): GIS-based land suitability analysis of sustainable hillside development. - Procedia Engineering 77: 87-94.

[7] Change, I. C. (2007): Climate change impacts, adaptation and vulnerability-summary for policy makers. - Contribution of Working Group I to the Fourth Assessment Report of the Intergovernmental Panel on Climate Change, Paris 12: 171-175.

[8] Chen, G., Fang, Y. et al. (2010): Development Report of Mountainous Area in China. China Commerce and Trade Press, Beijing (in Chinese).

[9] Chen, M., Qin, X., Zeng, G., Li, J. (2016): Impacts of human activity modes and climate on heavy metal "spread" in groundwater are biased. - Chemosphere 152: 439-445.

[10] Cui, P. (2014): Progress and prospects in research on mountain hazards in China. Progress in Geography 33(2): 145-152 (in Chinese).

[11] Dang, L., Xu, Y., Tang, Q. (2015): The pattern of available construction land along the Xijiang River in Guangxi, China. - Land Use Policy 42: 102-112.

[12] Deuskar, C., Baker, J. L., Mason, D. (eds.) (2015): East Asia's Changing Urban Landscape: Measuring a Decade of Spatial Growth. - World Bank Group, Washington, DC. FAO (1993): An international framework for evaluating sustainable land management. - World Soil Resources Report 73.

[13] Gimblett, R. H., Ball, G. L., Guisse, A. W. (1994): Autonomous rule generation and assessment for complex spatial modeling. - Landscape and Urban Planning 30(1-2): 1326. 
[14] Guo, X., Qiu, Y., Lian, G. et al. (2003): The progress and prospect of land quality indicators based on 'Press-State-Response' framework. - Progress in Geography 5: 479489 (in Chinese).

[15] Hemingway, R., Gunawan, O. (2018): The Natural Hazards Partnership: a public-sector collaboration across the UK for natural hazard disaster risk reduction. - International Journal of Disaster Risk Reduction 27: 499-511.

[16] ISDR (2005): Hyogo framework for action 2005-2015: building the resilience of nations and communities to disasters. - In: Extract from the final report of the World Conference on Disaster Reduction (A/CONF. 206/6, Vol. 380).

[17] Jiao, S., Zhang, X., Xu, Y. (2017): A review of Chinese land suitability assessment from the rainfall-waterlogging perspective: Evidence from the Su Yu Yuan area. - Journal of Cleaner Production 144: 100-106.

[18] Leroi, E., Bonnard, C., Fell, R., McInnes, R. (2005): Risk assessment and management. Landslide Risk Management 159-198.

[19] Liu, Y., Peng, J., Han, Y., Wei, H., Du, Y. (2014): Suitability assessment for building land consolidation on gentle hillside based on OWA operator: a case in Dali Bai Nationality Borough in Yunnan. - Acta Ecologica Sinica 34(12): 3188-3197 (in Chinese).

[20] Liu, Y., Peng, J., Zhang, T., Zhao, M. (2016): Assessing landscape eco-risk associated with hilly construction land exploitation in the southwest of China: Trade-off and adaptation. - Ecological Indicators 62: 289-297.

[21] Lovell, S. T. (2010): Multifunctional urban agriculture for sustainable land use planning in the United States. - Sustainability 2(8): 2499-2522.

[22] Malczewski, J. (2006): Ordered weighted averaging with fuzzy quantifiers: GIS-based multicriteria evaluation for land-use suitability analysis. - International Journal of Applied Earth Observation and Geoinformation 8(4): 270-277.

[23] Montanarella, L., Nègre, T. (2001): The development of the Alpine soil information system. - International Journal of Applied Earth Observation and Geoinformation 3(1): 18-24.

[24] Nan, X. (2009). Study on suitability evaluation of mountainous city construction land supported by GIS. - Northwest University (in Chinese).

[25] Peng, J., Ma, J., Du, Y., Zhang, L., Hu, X. (2016): Ecological suitability evaluation for mountainous area development based on conceptual model of landscape structure, function, and dynamics. - Ecological Indicators 61: 500-511.

[26] Promper, C., Puissant, A., Malet, J. P., Glade, T. (2014): Analysis of land cover changes in the past and the future as contribution to landslide risk scenarios. - Applied Geography 53: 11-19.

[27] Qiu, L., Zhu, J., Pan, Y., Hu, W., Amable, G. S. (2017): Multi-criteria land use suitability analysis for livestock development planning in Hangzhou metropolitan area, China. Journal of Cleaner Production 161: 1011-1019.

[28] Rusdi, M., Roosli, R., Ahamad, M. S. S. (2015): Land evaluation suitability for settlement based on soil permeability, topography and geology ten years after tsunami in Banda Aceh, Indonesia. - The Egyptian Journal of Remote Sensing and Space Science 18(2): 207-215.

[29] Smith, K. (2013): Environmental Hazards: Assessing Risk and Reducing Hazard. Routledge, New York.

[30] The State Council of China (2017): The National Comprehensive Disaster Prevention and Mitigation Plan (Year 2016-2020). - http://www.gov.cn/xinwen/201701/13/content_5159563.htm.

[31] United Nations Development Programme (UNDP) (2004): Bureau for Crisis Prevention, Recovery. Reducing Hazard Risk: A Challenge for Development. - A Global Report, United Nations. 
[32] Wang, H. (2012): Study on the suitability evaluation of urban construction land in southwest China: A case study of Yunnan Rili. - Yunnan University Finance and Economics, Yunnan (in Chinese).

[33] Wang, X., Bao, Y. (2011): Study on the methods of land use dynamic change research. Progress in Geography 18: 81-87 (in Chinese).

[34] Wei, H., Qin, B., Peng, J., Jin, X. (2014): Evaluation on comprehensive exploitation suitability of low-slope hilly land based on GRNN model and neighborhood calculation: A case study of Wumeng Mountain continuous poverty-stricken region. - Geographical Research 33(5): 831-841 (in Chinese).

[35] Wu, M., Zhang, C., Fan, T. (2016): Stress state of the Baoxing segment of the southwestern Longmenshan Fault Zone before and after the M s 7.0 Lushan earthquake. Journal of Asian Earth Sciences 121: 9-19.

[36] Ying, J., Yin, Z., Xu, S. et al. (2009): Disaster risk theory and risk management method. Journal of Catastrophology 24: 7-15 (in Chinese).

[37] Zhang, G. P., Xu, J., Bi, B. G. (2009): Relations of landslide and debris flow hazards to environmental factors. - The Journal of Applied Ecology 20(3): 653-658.

[38] Zhou, Q., Su, W. Chen, S. (2010): LUCC analysis of Tongliang County based on the landscape pattern indices and the Markov model. - Resources and Environment in the Yangtze Basin 19(7): 770-775 (in Chinese). 